\title{
THE HEMODYNAMIC RESPONSE TO ACOUSTICALLY MODIFIED SYLLABLES IN PREMATURE AND FULL TERM NEWBORN INFANTS ACQUIRED BY NEAR INFRARED SPECTROSCOPY
}

\author{
María Elizabeth Mónica Carlier-Torres ${ }^{1}$, Thalia Harmony ${ }^{1}$, Josefina Ricardo-Garcell ${ }^{*}$, \\ José L. Marroquín ${ }^{2}$, Miguel Colmenero ${ }^{1}$ \\ ${ }^{1}$ Instituto de Neurobiología, Unidad de Investigación en Neurodesarrollo, Universidad Nacional Autónoma de México, \\ Querétaro, México, ${ }^{2}$ Centro de Investigación en Matemáticas, Guanajuato, México
}

Recibido, abril 25/2014

Concepto de evaluación, mayo 5/2014

Aceptado, mayo 27/2014
Referencia: Carlier-Torres, M.E.M., Harmony, T., RicardoGarcell, J., Marroquín, J.L. \& Colmenero, M. (2014). The hemodynamic response to acoustically modified syllables in premature and full term newborn infants acquired by near infrared spectroscopy. Acta Colombiana de Psicología, 17 (2), pp. 13-21. DOI:10.14718/ACP.2014.17.2.2

\begin{abstract}
This research assesses, in newborns, the hemodynamic response to acoustically modified syllables (pronounced in a prolonged manner), versus the response to unmodified syllables (pronounced at a normal rate). The aim was to assess which of these stimulation conditions produced better syllable discrimination in two groups of neonates: 13 preterm (mean gestational age 30 weeks, SD 3 weeks), and 13 full term newborns (mean age 38 weeks, SD 1 week). Syllable discrimination, in each condition, was assessed by using an oddball paradigm (equal syllable trials vs. different syllable trials). The statistical analysis was based on the comparison between the hemodynamic response [oxyHbO] obtained by Near Infrared Spectroscopy (NIRS) to different syllable trials vs. equal syllable trials, in each condition. The modified syllable condition was better in producing trial discrimination in both groups. The amplitude of the hemodynamic response to the different syllable trials was greater than the one to the equal syllable trials: for term infants, $\mathrm{t}=2.59, \mathrm{p}=0.024$, and for preterm $\mathrm{t}=2.38, \mathrm{p}=0.035$. This finding occurred in the left temporal lobe. These data suggest that the modified syllables facilitate processing of phonemes from birth.

Key words: Preterm neonates, language acquisition, acoustically modified syllables, auditory temporal processing, Near Infrared Spectroscopy.
\end{abstract}

\section{RESPUESTA HEMODINÁMICA A SÍLABAS MODIFICADAS ACÚSTICAMENTE EN RECIÉN NACIDOS PREMATUROS YA TÉRMINO ADQUIRIDA POR ESPECTROSCOPÍA DEL INFRARROJO CERCANO}

\author{
Resumen
}

\begin{abstract}
Esta investigación evalúa, en neonatos, la respuesta hemodinámica ante sílabas modificadas acústicamente (pronunciadas de manera prolongada) en comparación con la respuesta a sílabas no modificadas (pronunciadas a una velocidad normal). El objetivo fue evaluar cuál de estas condiciones de estimulación producía una mejor discriminación silábica en dos grupos de neonatos: 13 prematuros (edad gestacional promedio de 30 semanas, DE 3 semanas) y 13 nacidos a término (edad gestacional promedio de 38 semanas, DE 1 semana). La discriminación de sílabas, en cada condición, se evaluó mediante un paradigma oddball (ensayos con sílabas iguales vs. ensayos con sílaba diferente). El análisis estadístico se basó en la comparación de la
\end{abstract}

\footnotetext{
* Unidad de Investigación en Neurodesarrollo, Instituto de Neurobiología, UNAM. Blvd. Juriquilla 3001 Querétaro, Qro., C.P. 76230. México.oojrg@yahoo.com

This project was partially supported by PAPIIT IN220110 from DGAPA UNAM, SALUD-2009-01-112217 from CONACyT. The first author wishes to thank The Doctoral Program in Psychology/Universidad Nacional Autónoma de México and the CONACyT scholarship No. 34487. The authors also wish to thank Nurse Delia Figueroa, and engineer Hector Belmont for their support during data acquisition, and Dr. Gloria Avecilla-Ramirez for providing the non-modified syllables. We would also like to thank Dr. Pilar Mejía Valdés, and Nurse Rosa Alicia Romero Carrillo from the Hospital del Niño y la Mujer for their support in the selection of the participants.
} 
respuesta hemodinámica [oxyHb] obtenida por espectroscopia de infrarrojo cercano (NIRS) ante ensayos con sílabas iguales Vs. ensayos con una sílaba diferente en cada condición. Se encontró que la condición de sílabas modificadas obtuvo mejores resultados para la discriminación entre ensayos en ambos grupos. La amplitud de la respuesta hemodinámica ante el ensayo con una sílaba diferente fue significativamente mayor que ante el ensayo con sílabas iguales: en recién nacidos a término, $\mathrm{t}=2,59, \mathrm{p}=0,024$ y en los prematuros, $\mathrm{t}=2,38, \mathrm{p}=0,035$. Este hallazgo ocurrió en el lóbulo temporal izquierdo. Estos datos sugieren que las sílabas modificadas facilitan el procesamiento de fonemas desde el nacimiento.

Palabras clave: neonatos prematuros, adquisición del lenguaje, habla modificada acústicamente, procesamiento auditivo temporal, espectroscopia del infrarrojo cercano.

\title{
RESPOSTA HEMODINÂMICA A SÍLABAS MODIFICADAS ACUSTICAMENTE EM RECEM-NASCIDOS PREMATUROS E A TERMO ADQUIRIDA POR ESPECTROSCOPIA DO INFRAVERMELHO PRÓXIMO
}

\author{
Resumo
}

\begin{abstract}
Esta pesquisa avalia, em neonatos, a resposta hemodinâmica diante sílabas modificadas acusticamente (pronunciadas de maneira prolongada) em comparação com a resposta a sílabas não modificadas (pronunciadas a uma velocidade normal). O objetivo foi avaliar qual destas condições de estimulação produzia uma melhor discriminação silábica em dois grupos de neonatos: 13 prematuros (idade gestacional média de 30 semanas, DE 3 semanas) e 13 nascidos a termo (idade gestacional média de 38 semanas, DE 1 semana). A discriminação de sílabas, em cada condição, foi avaliada mediante um paradigma oddball (ensaios com sílabas iguais vs. ensaios com sílaba diferente). A análise estadística se baseou na comparação da resposta hemodinâmica [oxyHb] obtida por espectroscopia de infravermelho próximo (NIRS) ante ensaios com sílabas iguais Vs. ensaios com uma sílaba diferente em cada condição. Encontrou-se que a condição de sílabas modificadas obteve melhores resultados para a discriminação entre ensaios em ambos os grupos. A amplitude da resposta hemodinâmica ante o ensaio com uma sílaba diferente foi significativamente maior que perante o ensaio com sílabas iguais: em recém-nascidos a termo, $\mathrm{t}=2,59, \mathrm{p}=0,024$ e nos prematuros, $\mathrm{t}=2,38, \mathrm{p}=0,035$. Este descobrimento ocorreu no lóbulo temporal esquerdo. Estes dados sugerem que as sílabas modificadas facilitam o processamento de fonemas desde o nascimento.

Palavras chave: neonatos prematuros, aquisição da linguagem, fala modificada acusticamente, processamento auditivo temporal, espectroscopia do infravermelho próximo.
\end{abstract}

\section{INTRODUCTION}

Preterm infants are at a higher risk of developing cognitive disorders than healthy full term infants (Ortiz-Mantilla, Choudhury, Leevers, \& Benasich, 2008; Peña, Pittaluga, \& Mahler, 2010; Harmony, Alba, Marroquin, Fernández-Bouzas, Avecilla, Ricardo-Garcell et al., 2009; Bosh, 2011) and these cognitive disorders are often manifested as language development problems (Kurtzberg, Hilpert, Kreuzer, \& Vaughan, 1984). Several studies support the hypothesis that such language problems, in presence of normal hearing, are associated with disorders of basic skills of cortical auditory processing during early development (Kurtzberg et al., 1984; Trehub \& Henderson, 1996; Benasich \& Tallal, 1996). Such disorders prevent infants from representing speech phonemes accurately, and this is going to be apparent in preschoolers. That is the time when children must develop phoneme awareness. Phonological awareness is necessary to learn a language and it involves the ability to intentionally manipulate sound structures of words from a substitution of a sound to a segmentation into smaller units (Suehiro \& Dos Santos, 2011). Impairments in this skill trigger deficiencies in other skills such as reading and writing (Montealegre \& Forero, 2006). It is important to note that many other cognitive abilities affect language acquisition and thus they have shown to be involved in an atypical language development; however, the present research focuses on auditory temporal processing early in life.

Benasich and Tallal (1996) studied the speed of auditory stimuli processing in healthy, full-term infants at six months of age by examining habituation and recognition memory. They found a relationship among habituation, recognition memory and processing of acoustic temporal cues (auditory temporal processing): those infants who were able to process rapidly (lower auditory temporal processing thresholds) also habituated more efficiently (fewer trials to criterion and steeper habituation slopes) and discriminated better (higher scores for novel image recognition memory).

Harmony et al. (2009) studied oscillatory brain activity during the processing of syllables and tones in normal infants and in infants with Periventricular Leukomalacia (PVL) at 46 weeks postconceptional age. They found that in normal infants, increases of power compared to the value prior to 
the stimulus were greater for syllables than for tones, but in infants with PVL, such increases were smaller for syllables than for tones. Oscillatory brain activity at 46 weeks postconceptional age in response to repeated auditory stimuli could discriminate between preterm infants that later, at the age of 14 months, scored high or low on a standard language inventory (Avecilla-Ramírez, Ruiz-Correa, Marroquín, Harmony, Alba \& Mendoza-Montoya, 2011).

These studies show that preterm infants may have cognitive limitations that impede typical language acquisition. The perception of phonemes during the first year of life is critical because in this period infants represent the phonemes of their mother tongue. This representation requires precise perception of the rapid transitions between phonemes which are the cue to discriminate them (Pisoni, 1973; Stevens, 2000). The perception of such cues requires rapid integration at the sensory processing level(Heim, Friedman, Keil, \& Benasich, 2011). It has been shown that difficulties in the decoding of such cues

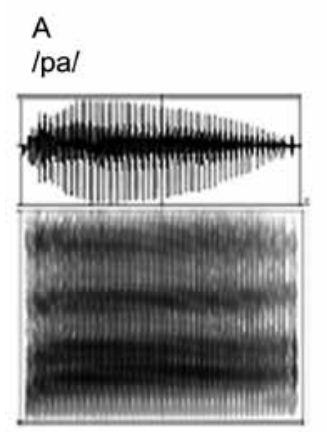

B /pa/

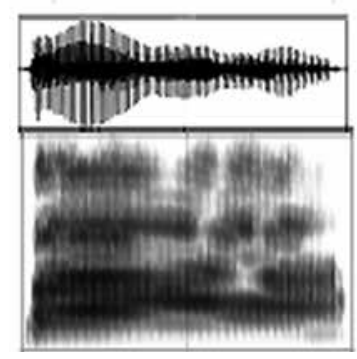

/tal

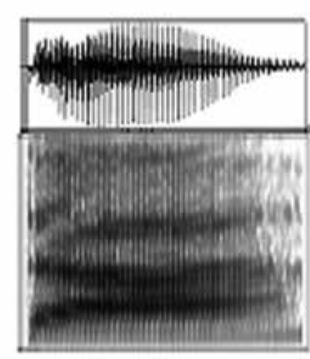

Ital

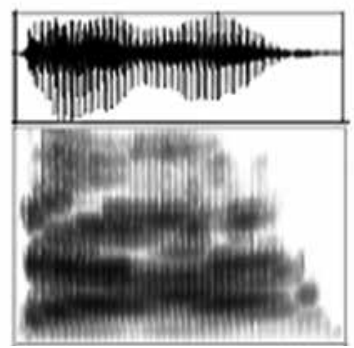

Figure 1. Waveforms and spectrograms for the syllables $/ \mathrm{pa} / \mathrm{y} / \mathrm{ta} /$. Time is represented on the abscissa ( $0-260 \mathrm{~ms}$ for non-modified, and 0-390 ms for modified syllables) and amplitude and frequency (0$5000 \mathrm{~Hz}$ ) on the ordinate. The darkness of the trace in each frequency/time region is controlled by the amount of energy in the signal at that particular frequency and time. A and B syllables in the non-modified condition. $\mathrm{C}$ and $\mathrm{D}$ syllables in the modified condition. In both condition the syllables were matched for intensity (76dB). In each condition the syllables were matched for total duration (260 ms for the non-modified condition, and $390 \mathrm{~ms}$ for the modified condition). The duration of the formant transition for the non-modified condition was about $45 \mathrm{~ms}$, and for the modified condition was about $90 \mathrm{~ms}$. are associated with language deficits in school-age children (Tallal, Miller, Bedi, Byma, Wang, Nagarajan, et al. 1996; Merzenich, Jenkins, Jonson, Schreiner, Miller, Tallal, 1996) and are predictive of language skills when examined in infancy (Benasich \& Tallal, 2002; Choudhury, \& Benasich, 2011).

One approach to enhance the impairment in perception of rapid auditory cues of school-age children is to use acoustically modified syllables to lengthen the duration of the transition between phonemes and enhance the contrast between them (Narajaran, Wang, Merzenich, Shreiner, Johnston, Jenkins, et al. 1998). No studies have been done to examine the processing of acoustically modified syllables in infants at risk of language development problems such as preterm newborns. Therefore, this research was aimed to study the hemodynamic responses of full term and preterm newborn babies to syllables acoustically modified and unmodified by using a paradigm similar to an oddball to assess which condition was better in producing discrimination of syllables.

\section{METHOD}

\section{Participants}

Thirteen preterm newborns, 8 males and 5 females, and thirteen full term healthy newborns, 9 males and 4 females were studied. Mean gestational age for the preterm infants was 30 weeks (SD 3 weeks, range 26 to 35) with mean birth weight of $1474 \mathrm{gr}$ (SD $212 \mathrm{gr}$, range 1000 to $2500 \mathrm{gr}$ ). Infants were tested at the postconceptional age of 38 weeks. The initial sample was of 18 infants but 5 of them had to be excluded from further data analysis as a result of low signal to noise ratio $(n=3)$ or infant's discomfort $(n=2)$.

The preterm infant sample was at the Weight Increase Room of the Children and Women Hospital in Querétaro, México (Sala de Incremento de Peso del Hospital del Niño $y$ la Mujer). The physical conditions of the preterm and full term newborns were assessed by the pediatrician of the hospital with the standard newborn screening. This screening included measuring otoacoustic emissions to assess the newborns' hearing abilities. All infants had normal hearing values.

\section{Instruments}

\section{Stimuli}

The phonetic stimuli consisted of two consonant-vowel syllables /ta/ and $/ \mathrm{pa} /$ naturally produced by a female adult whose mother tongue was Spanish. The same syllables were acoustically modified to prolong the duration of the formant transition, and to create a more salient version of the rapidly changing elements in the acoustic waveform of speech. The acoustical modification was done using Praat, a free computer software package for the analysis of speech 
(Boersma \& Weenink, 2013). Such modification was done following procedures similar to those proposed by Nagarajan et al. (1998) but not identical to the algorithm they proposed. The signal was prolongued by $50 \%$ and applied an emphasis algorithm available in Praat to enhance the contrast between phonemes. See Figure 1.

\section{Paradigm of Stimulation}

The paradigm was adapted from the one used in the study by Dehaene-Lambertz \& Dehaene (1994) with full term healthy infants. The syllables were presented in groups (or trials) of four at $890 \mathrm{~ms}$ intervals from onset to onset. There were two types of trials, standard (equal syllable trials) and deviant (different syllable trials). On standard trials, the syllable /ta/ was repeated four times (/ta/ / ta/ / ta/ $/ \mathrm{ta} /)$, whereas on deviant trials the syllable $/ \mathrm{pa}$ / was repeated three times and the phonetic change was introduced in the fourth position (/pa//pa//pa//ta/). Standard and deviant trials were organized into 16 blocks of three equal trials with an intertrial interval of 2 seconds, and a variable interblock interval of 20 and 30 seconds. Two paradigms were designed, one for

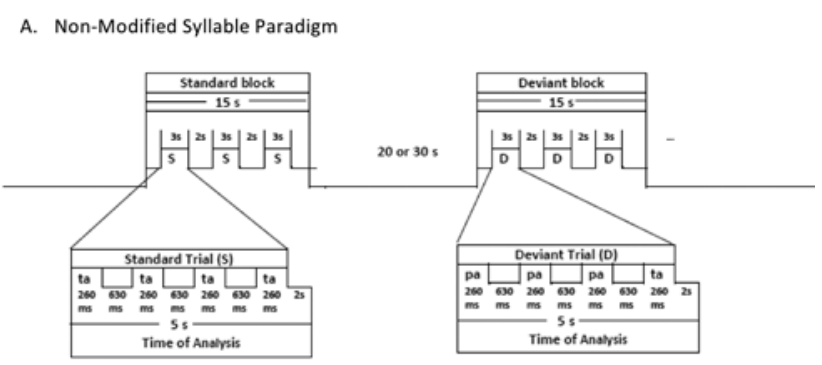

B. Modified syllable condition

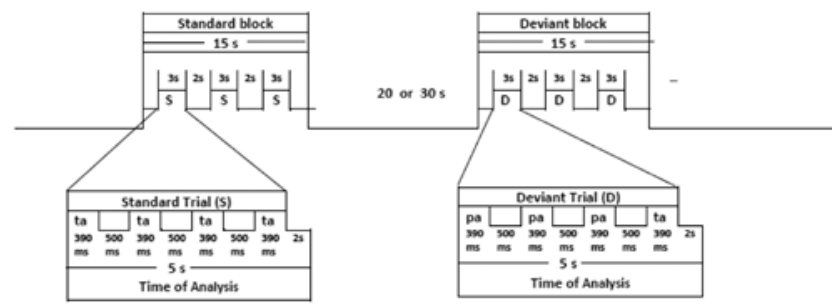

Figure 2. Time chart for the non-modified and modified syllables paradigm of stimulation. A. It describes the non-modified syllable paradigm. B. It describes the modified syllable paradigm. The two paradigms are equal, both are made of sixteen blocks, eight standard and eight deviant, presented in an interleave order. Both last $11 \mathrm{~min}$. To match the differences in the length of syllables we drove an intersyllables interval longer for non-modified syllables condition. The paradigm was presented to the infant one after the other, and the presentation was counterbalance among subjects. the unmodified syllables, and the other one for the modified syllables (see Figure 2). The order of presentation of each condition was counterbalanced among subjects.

\section{Procedure}

Neonates were tested in a silent, private experimental room at the Children and Women Hospital in Querétaro, México. Infants were asleep in a bassinet. The stimuli were presented via two high-quality stereo speakers located 100 $\mathrm{cm}$ away from each of the infant's ears. The sound level was set to $76 \mathrm{~dB}$ (SPL). A Windows desktop computer running Mind Tracer on Windows 98 controlled the experiment, triggering the language stimuli and sending markers to the NIRS machine.

The newborns were exposed to both conditions, one after the other. The experiment lasted approximately 40 min including the time for preparing the infants. The whole procedure was well tolerated by the newborns. The experiment was discontinued if the infant showed any sign of discomfort.

\section{Data collection}

Optical topography. Neural activity is accompanied by changes in blood oxygenation; therefore the concentrations of oxygenated hemoglobin [oxyHb] and deoxygenated hemoglobin [deoxyHb] in brain tissue are indicators of neural activity (Gervain, Mehler, Werker, Nelson, Csibra, Lloyd-Fox, et al. 2011). The changes of concentration of $[\mathrm{oxyHb}]$ and [deoxyHb] can be detected by near-infrared light systems. Cortical oxygenation changes were measured using near infrared spectroscopy to assess the cortical vascular response to the auditory stimuli. Spectroscopic assessment of cortical concentration changes in oxygenated hemoglobin [oxyHb] and deoxygenated hemoglobin [deoxyHb] can be derived from changes in attenuation at two wavelengths. The physical and physiological principles underlying optical imaging have been introduced and discussed in great detail in different studies (Villringer \& Chance, 1997; Obrig \& Villringer, 2003; Wartenburger, Steinbrink, Telkemeyer, Friedrich, Friederici, Obrig, 2007).

In the present study a Hitachi ETG-4000 NIRS machine with a source detector separation of $3 \mathrm{~cm}$. was used. The volumes measured correspond approximately to the cortical area underlying each emitter-detector pair. Optical topography data were continuously sampled at $10 \mathrm{~Hz}$, and attenuation changes at 690 and $830 \mathrm{~nm}$ were converted into changes in [oxyHb] and [deoxyHb] by the modified Lambert-Beer approach (Cope \& Delpy, 1988). For further technical details regarding the machine, see Gervain et al. (2011). 


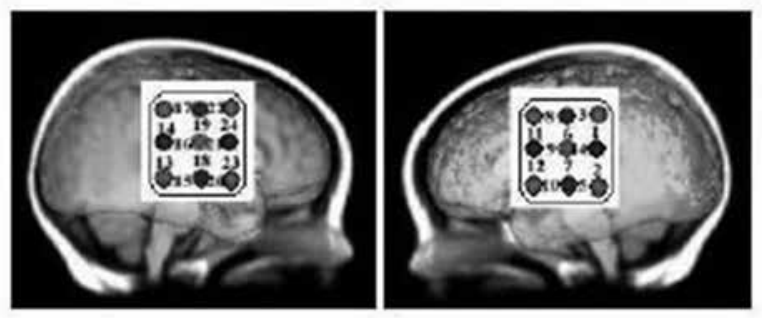

Figure 3. Configuration of probes sets overlaid on a schematic infant head. The hemodynamic response was recorded from six measurement positions per hemisphere represented by all available emitterdetector pairs placed on the temporal lobe. These measurements positions are represented for numbers. Grey circles indicate emitter fibers, while black circles indicate detectors. Separation in all emitter-detector channels was $3 \mathrm{~cm}$. Probes were place so that the bottom-most channels (5 and 10 in the left hemisphere, and 15 and 20 in the right hemisphere) ideally nestle over the infant's ear.

Two optical probes were used each consisting of nine $1 \mathrm{~mm}$ optical fibers. Of these nine fibers, five were emitters and four detectors. There were 12 recording channels in each probe. One probe set was placed over the temporal lobe area of the neonate's scalp of the left hemisphere; the second probe set was placed over the symmetrical area of the right hemisphere. The probes were situated to nestle above the infant's ears (Figure 3). A stretchy cap held the probes on the skull.

\section{Data Analysis}

In order to improve the signal to noise ratio, a low-pass filter was employed. The data was smoothing by convoluting it with the hemodynamic response function (hrf). This averaging reduces the high frequency components of the data. In addition, to remove an unknown global trend due to breathing, or cardiac vaso-motion, a wavelet transform was applied. Both techniques are implemented in NIRS SPM software (Ye, Tak, Jang, Jung, Jang, 2009; Li, Tak, \& Ye, 2012). The region of interest, ROI, in each hemisphere, was defined by the six measurement positions over each hemisphere covering the temporal lobe, similar to previous studies such as the ones by Peña, Maki, Kovacic, DehaeneLambertz, Koizumi, \& Bouquet (2003) and May, ByerssHeinlein, Gervain, \& Werker (2011). As for this study, in the left hemisphere, channel 4 and 2 correspond to the posterior temporal gyrus region, 4 to the superior part, and 2 to the inferior part. Channels 7 and 5 to the media temporal gyrus, superior and inferior respectively, and channels 12 and 10 to the anterior temporal gyrus, superior and inferior respectively. Similarly, in the right hemisphere, channel 16 and 13 correspond to the posterior temporal gyrus, channel 18 and 15 to the media temporal gyrus, and channel 20 and 23 to the anterior temporal gyrus. (see Figure 3).

Analysis was conducted on [oxyHb] in a time window between 0 and 5 seconds after the stimulus onset to capture the time course of the hemodynamic response of the first trial of each block (See Figure 2). The analysis focused on the first trial of each block because the [oxyHb] response to this first trial was of greater amplitude than the one to the other trials of the block in the full term healthy infants.

The statistical analysis was based on the comparison between the $[0 x y H b O]$ responses to the deviant stimulus vs. to the standard stimulus. This statistical analysis was done in two stages. In the first stage, individual analysis of each subject's [oxyHb] concentration changes in response to each type of stimulus (deviant and standard) in each condition (modified and unmodified) per channel was performed. This individual analysis was based on the general linear model, expressed in the following general equation $Y=X_{1} \beta_{1}+X_{2} \beta_{2}+\ldots X_{n} \beta_{n}+\varepsilon$. This model expresses the observed response in terms of a linear combination of explanatory variables, $\mathrm{X}_{1}, \mathrm{X}_{2} \ldots, \mathrm{X}_{\mathrm{n}}$, where $\mathbf{n}$ represents the number of variables or conditions of the experiment. In this case there are two explanatory variables which are the deviant and the standard syllables trials. The regression coefficients, $\beta$ s, relate the observed data with the explanatory variables. In this type of statistical analysis the null hypothesis is $\beta=0$ and the alternative is $\beta<>0$. The higher the regression coefficient, the greater is the effect of the condition on the observed signal. This model allows us to evaluate the effect of each type of stimulus (deviant vs. standard) in each condition (modified and unmodified syllables) per channel on the observed data. In the second stage, statistical comparisons of individual $\beta$ s per channel between types of stimuli (deviant and standard trial of syllables) and between left and right hemispheres, in each condition (modified and unmodified), were made using a Student $t$ test for dependent samples.

\section{Ethical considerations}

The Ethics committee of the Instituto de Neurobiologia of the Universidad Nacional Autónoma de México approved this study which also complies with the Ethical Principles for Medical Research Involving Human Subjects established by the Declaration of Helsinki. Informed written parental consent for participation in this study was obtained for all subjects.

\section{RESULTS}

In the first place, averages across both types of stimuli (deviant and standard trial) were obtained over all probe 
A. Full term non-modified syllable condition.

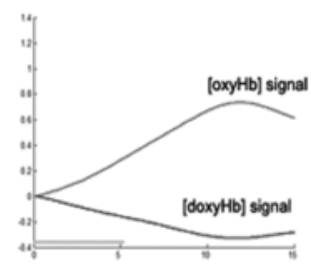

C. Preterm non-modified syllable condition.

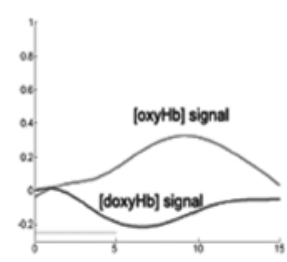

B. Full term modifies syllable condition.

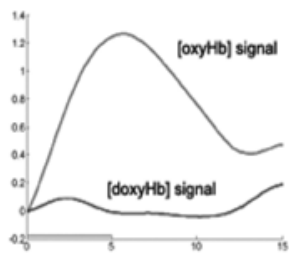

D. Preterm modified syllable condition

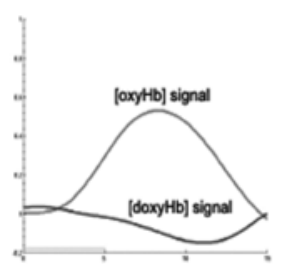

Figure 4. Hemodynamic response to sound versus silence periods. Time course of the grand average across all types of stimuli (deviant and standard) averaged over all measured probe positions. The $y$-axis represents the hemodynamic concentration changes (measured here in arbitrary units). The $\mathrm{x}$-axis displays the time in seconds. The gray line along the $\mathrm{x}$-axis illustrates the time of analysis (stimulation is delivered at time zero). A. Full term group in the non-modified syllable condition. The [oxyHb] signal peaks at $12.5 \mathrm{~s}$. B. Full term group in the modified syllable condition. The [oxyHb] signal peaks at 5.6 s. C. Preterm group in the nonmodified syllable condition. The [oxyHb] signal peaks at $9.3 \mathrm{~s}$. D. Preterm group in the modified syllable condition. The [oxyHb] signal peaks at $8.2 \mathrm{~s}$.

positions of the ROI in each condition (unmodified and modified syllables) to assess the hemodynamic response during sound periods compared with silence periods per group (full term and preterm neonates). Figure 4 illustrates the mean time course across both type of stimuli averaged over all measured probe positions in each group.

In a typical hemodynamic response function in adults, the response often starts with a small increase in [deoxyHb], followed by an increase in [oxyHb] and a decrease in [deoxyHb] concentrations. The signals peak some seconds after stimulus onset and then slowly return to baseline, with a possible under- and overshoot (Gervain et al., 2011). However, the hemodynamic response in infants does not always present the same characteristics of adults. Some research has found increase in both [oxyHb] and [deoxyHb] (Bortfeld, Wruck, \& Boas, 2007; Sakatani, Chenb, Lichtyc, \& Zuoa, 2009).

Next, an analysis was performed of whether the two types of stimuli, deviant vs. standard, resulted in differential hemodynamic responses in each condition (modified and unmodified syllables), both in the same hemisphere and between hemispheres. As mentioned before, the general linear model was applied and entered the $\beta$ values for the two different types of stimuli into a t test to compare deviant vs. standard stimuli in each channel position of the ROI and for each group (full term and preterm neonates).

The modified syllable was better in producing syllable discrimination. For both groups, in the modified syllable condition, the comparison between deviant and standard trials in the same hemisphere yielded the following results. The $[0 x y H b]$ response to the deviant trial was greater than the one to the standard trial only in the left hemisphere in channel 5 (for the full term infants, $t(13)=2.59, p=0.024$, and for the preterm $\mathrm{t}(13)=2.38, \mathrm{p}=0.035)$; whereas for both groups in the unmodified syllable condition no significant differences were found between standard and deviant trials in the same hemisphere. On the other hand, in both conditions and in both groups, the comparison of the [oxyHb] response to the same trial between left and right hemisphere yielded no significant differences.

\section{DISCUSSION}

The increase in the [oxyHb] response and the decrease of the [deoxyHb] response in both groups and both conditions (see figure 4) corresponds to the wellknown vascular response dynamics in newborns (Peña et al., 2003; Minagawa-Kawai, Mori, Naoi, \& Kojima, 2007; Gervain, Macagno, Cogoi, Peña, \& Mehler, 2008; Telkemeyer, Rossi, Koch, Nierhaus, Steinbrink, Poeppel, et al., 2009).), and in older infants (Cannestra, Wartenburger, Obrig, Villringer, \& Toga, 2003; Taga, Asakawa, Hirasawa, \& Konishi, 2003).

In both groups the increase in [oxyHb] response to the deviant block was greater than to the standard block only in the modified syllable condition in the left hemisphere. This result should lead to the statement that the modified syllables help to improve the discrimination of phonemes in both groups of infants. This difference between deviant and standard trials may indicate that there was greater neuronal activation for the deviant trial than for the standard one to meet the demand for the discrimination of the phonemes. As a consequence, the local cerebral blood flow was greater in the left hemisphere, since this hemisphere is in charge of the processing of rapid changes among phonemes (Poeppel, 2003; Zatorre, 2001) which is necessary for discrimination to occur. Here it is important to note that in both modified 
and unmodified syllable conditions the duration of rapid changes between phonemes is still within the range of rapid changes (less than about $100 \mathrm{~ms}$ (Telkemeyer et al., 2009 ) but the modified syllables (90 ms) with prolonged duration, are slower than the unmodified syllables (45 ms).

The place where the discrimination between types of trials occurred, channel 5, which corresponded to the inferior media temporal gyrus, is in line with the result of Telkemeyer et al. (2009) who also found the effect of the rapid modulations of non-verbal auditory stimuli on the channel placed on a similar location.

The fact that discrimination between standard and deviant trials was found only for the modified syllables in both groups strongly suggests that the prolongation of the consonant improves neural processing. This result may be applied in the future as the basis for an early treatment of premature infants with periventricular leukomalacia. In these infants, Avecilla et al. (2011) have shown that electrophysiological event-related oscillations may be used as predictors of language impairments; therefore they may be candidates for this type of treatment.

The bilateral processing of the trials is explained with the hypothesis proposed by Boemio and collaborators who stated that the processing of the spectro-temporal cues of the acoustic signal is bilateral since the left hemisphere processes the rapid spectro-temporal cues and the right hemisphere processes the slower spectro-temporal cues such as prosody (Boemio, Fromm, Braun, \& Poeppel, 2005).

On the other hand, it is possible that the discrimination of syllables pronounced at a normal rate of speech has been hampered because of the lack of experience in language in new born infants. It is known that when an adult is speaking to a new born he/she does it in a slow and exaggerated manner to make more emphasis on phonemes, a condition called speech directed to babies (Kuhl, Andruski, Chistovich, Chistovich, Kozhevnikova, Ryskina, et al. 1997). It has been proposed that speech directed to babies helps in language acquisition during infants first year of life and at the end of this year infants specialize in the processing of phonemes in their native tongue (Kuhl, 2004).

If a comparison is made between modified and unmodified syllables with speech directed to babies and speech directed to adults, respectively, a conclusion could be drawn that the response to unmodified syllables at a normal rate of speech could get better with age. However, since there is a possibility that a group of premature infants develop language problems, it is necessary to conduct future research to determine persistent language problems at an early age.

Overall, these data suggest that modified syllables facilitate processing of the rapid spectro-temporal characteristics of the syllables from birth. The results of this work, although not conclusive, lead to consider the study of acoustically modified syllables as a valuable resource for the design of early language therapies.

Such therapies should address cognitive problems that hinder precise perception of phonemes, since this is the main task of infants during the first year of life (Kuhl, 2004). One potential therapy is the use of acoustically modified syllables to lengthen the duration between the phonemes, thereby facilitating their perception. Although this method has generated a debate in the academic community (e.g. Studdert-Kennedy \& Mody, 1995) which is not related to preterm infants, but rather to older children, further studies are proposed in this direction.

Finally, NIRS is a brain imaging technique particularly suitable for young infants. Not all brain imaging techniques are suitable for the study of infants and children because of safety concerns and the need to be still for long periods of time. Beyond the practical benefits such as low operating costs, easy implementation and motion tolerance, NIRS is sensitive to pathological brain activity in infants. Since perinatal complications usually affect blood flow and oxygenation of the brain, exploring brain function in preterm infants with hypoxia will help our understanding of how these early traumas impact cognitive development (for a review see Gervain et al. 2011).

\section{Conflict of Interest Statement}

The authors have no conflicts of interest to disclose.

\section{REFERENCES}

Avecilla-Ramírez, G. N., Ruiz-Correa, S., Marroquín, J. L., Harmony, T., Alba A., \& Mendoza-Montoya, O. (2011). Electrophysiological auditory responses and language development in infants with leukomalacia. Brain and Language, 119, 175-183.

Benasich, A., \& Tallal, P. (1996). Auditory temporal processing thresholds, habituation, and recognition memory over the 1st year. Infant Behavior and Development, 19, 339-357.

Benasich, A., \& Tallal, P. (2002). Infant discrimination of rapid auditory cues predicts later language impairment. Behavioral Brain Research, 136, 31-49.

Boemio, A, Fromm, S., Braun, A., \& Poeppel, D. (2005). Hierarchical and asymmetric temporal sensitivity in human auditory cortices. Nature Neuroscience, 8, 389-395.

Boersma, P., \& Weenink, D. (2013). Praat: doing phonetics by computer (Version 5.3.60). [Computer software]. Retrieved March 23, 2013 from http://www.praat.org. 
Bortfeld, H., Wruck, E., \& Boas, D. (2007). Assessing Infants' Cortical Response to Speech Using Near-Infrared Spectroscopy. Neuroimage, 34 (1), 407-415.

Bosh, L. (2011). Precursors to language in preterm infants: Speech perception abilities in the first year of life. In O. Braddick, J. Atkinson, \& G. Innocenti (Eds). Gene Expression to Neurobiology and Behavior Human Brain Development and Developmental Disorders (pp. 239-257). Oxford, UK.

Cannestra, A.F., Wartenburger, I., Obrig, H., Villringer, A., \& Toga, A.W. (2003). Functional assessment of Broca's area using near infrared spectroscopy in humans. Neuroreport, 4 , 1961-1965.

Choudhury, N., \& Benasich, A. (2011). Maturation of auditory evoked potentials from 6 to 48 months: prediction to 3 and 4 year language and cognitive abilities. Clinical Neurophysiology, 122, 320-338.

Cope, M., \& Delpy, D.T. (1988). System for long-term measurement of cerebral blood and tissue oxygenation on newborn infants by near infra-red illumination. Medical \& Biological Engineering \& Computing, 26, 289-294.

Dehaene-Lambertz, G., \& Dehaene, S. (1994). Speed and cerebral correlates of syllable discrimination in infants. Nature, 370, 292-295.

Gervain, J., Macagno, F., Cogoi, S., Peña, M., \& Mehler, J. (2008). The neonate brain detects speech structure. Proceedings of the National Academy of Sciences of the U.S.A., 105 (37), 14222-14227.

Gervain, J., Mehler, J., Werker, J. F., Nelson, C. A., Csibra, C., Lloyd-Fox S., et al. (2011). Near-infrared spectroscopy: a report from the McDonnell infant methodology consortium. Developmental Cognitive Neuroscience, 1, 22-46.

Harmony, T., Alba, A., Marroquín, J. L., Fernández-Bouzas, A., Avecilla, G., Ricardo-Garcell, J., et al. (2009). Quantitative electroencephalography in the normal and abnormal developing human brain. In C. E. Riback, C. Arámburo de la Hoz, E. G. Jones, J. A. Larriva, \& L. W. Swanson (Eds), Development to degeneration and regeneration on the nervous system (pp. 103-117). Oxford University Press.

Heim, S., Friedman, J. T., Keil, A., \& Benasich, A. (2011). Reduced sensory oscillatory activity during rapid auditory processing as a correlate of language-learning impairment. Journal of Neurolinguistics, 24, 538-555.

Kuhl, P. K., Andruski, J. E., Chistovich, I. A., Chistovich, L. A., Kozhevnikova, E. V., Ryskina,et al. (1997). Cross-language analysis of phonetics units in language addressed to infants. Science, 277, 684-686.

Kuhl, P. (2004). Early language acquisition: Cracking the speech code. Nature Review Neuroscience 5, 831-843.

Kurtzberg, D., Hilpert, P.L., Kreuzer, J. A., \& Vaughan, H. G. (1984). Differential maturation of cortical auditory evoked potentials to speech sound and normal full term and very low-birth weight infants. Developmental Imaging and Child Neurology, 26, 466-475.
Li, H., Tak, S., \& Ye, J. C. (2012). Lipschitz Killing curvature based expected Euler characteristics for p-value correction in fNIRS. Journal of Neuroscience Methods, 204, 61-67.

May, L., Byerss-Heinlein, K., Gervain, J., \& Werker, J. (2011). Language and the newborn brain: does prenatal language experience shape the neonate neural response to speech? Frontiers in Psychology, 2, 3-9.

Merzenich, M. M., Jenkins, W. M., Jonson, P., Schreiner, C., Miller, S.L., Tallal, P. (1996). Temporal processing deficit of language-learning impaired children ameliorated by training. Science, 271, 77-81.

Minagawa-Kawai Y, Mori K, Hebden JC, \& Dupoux E. (2008). Optical imaging of infants' neurocognitive development: recent advances and perspectives. Developmental Neurobiology, 68, 712-728.

Minagawa-Kawai, Y., Mori, K., Naoi, N., \& Kojima, S. (2007). Neural attunement processes in infants during the acquisition of a language-specific phonemic contrast. Journal of Neuroscience 27 (2), 315-321.

Montealegre, R., \& Forero, L.D. (2006). Desarrollo de la lectoescritura: Adquisición y Dominio [Development of Reading/writing skills: acquisition and dominion]. Acta Colombiana de Psicología, 9 (1), 25-40.

Narajaran, S. S., Wang, X., Merzenich, M. M, Shreiner, C. E., Johnston, P., Jenkins, W. M., et al. (1998). Speech modification algorithms used for training language learningimpaired children. IEEE Transactions on Rehabilitation Engineering 6, 257-268.

Obrig, H., \& Villringer, A. (2003). Beyond the visible--imaging the human brain with light. Journal of Cerebral Blood Flow \& Metabolism, 23, 1-18.

Ortiz-Mantilla, S., Choudhury, N., Leevers, H., \& Benasich, A. (2008). Understanding language and cognitive deficits in very low birth weight children. Developmental Psychobiology, 50, 107-126.

Peña, M., Maki, A., Kovacic, D., Dehaene-Lambertz, G., Koizumi, H., \& Bouquet, F. (2003). Sounds and silence: an optical topography study of language recognition at birth. Proceedings of the National Academy of Sciences of the U.S.A., 100, 11702-11705.

Peña, M., Pittaluga, E., \& Mehler, J. (2010). Language acquisition in premature and full-term infants. Proceedings of the National Academy of Sciences of the U.S.A., 107, 38233828.

Pisoni, D. (1973). Auditory and phonetic memory codes in the discrimination of consonants and vowels. Perception and Psychophysics, 13, 253-260.

Poeppel, D. (2003). The analysis of speech in different temporal integration windows: cerebral lateralization as "asymmetric sampling in time." Speech Communication 41, 245-255.

Sakatani, K., Chenb, S., Lichtyc, W., \& Zuoa, H. (2009). Cerebral blood oxygenation changes induced by auditory stimu- 
lation in newborn infants measured by near infrared spectroscopy. Early Human Development, 55, 229-236.

Stevens, K. N. (2000). Acoustic Phonetics. Cambridge, MA.: MIT Press.

Studdert-Kennedy, M., Mody, M. (1995) Auditory temporal perception deficits in the reading-impaired: A critical review of the evidence. Psychonomic Bulletin \& Review 2 (4), 508-514.

Suehiro, A. C. B., \& Dos Santos, A. A. A. (2011). Roteiro de avaliação da Consciência fonológica (RACF) [Roadmap assessment of phonological awareness (RACF)]. Acta Colombiana de Psicología, 14 (1), 147-154.

Taga, G., Asakawa, K., Hirasawa, K., \& Konishi, Y. (2003). Hemodynamic responses to visual stimulation in occipital and frontal cortex of newborn infants: a near-infrared optical topography study. Early Human Development, 75, S203-S210.

Tallal, P., Miller, S., Bedi, G., Byma, G., Wang, X., Nagarajan, S., et al. (1996). Language comprehension in language learning impaired children improved with acoustically modified speech. Science, 271, 81-84.
Telkemeyer, S., Rossi, X., Koch, S.P., Nierhaus, T., Steinbrink, J., Poeppel, D., et al. (2009). Sensitivity of Newborn Auditory Cortex to the Temporal Structure of Sounds. The Journal of Neuroscience, 29, 14726 -14733.

Trehub, S.E., \& Henderson, J. L. (1996). Temporal resolution in infancy and subsequent language development. Journal of Speech and Hearing Research, 39, 1315-1320.

Villringer, A., \& Chance, B. (1997). Non-invasive optical spectroscopy and imaging of human brain function. Trends in Neurosciences, 20, 435-442.

Wartenburger, I., Steinbrink, J., Telkemeyer, S., Friedrich, M., Friederici, A.D., Obrig, H. (2007). The processing of prosody: evidence of interhemispheric specialization at the age of four. Neuroimage, 34, 416-425.

Ye, J.C., Tak, S., Jang, K.E., Jung, J., Jang, J. (2009). NIRSSPM: Statistical parametric mapping for near-infrared spectroscopy. NeuroImage, 44, 428-447.

Zatorre, R.J., Belin, P. (2001). Spectral and temporal processing in human auditory cortex. Cerebral Cortex, 11, 946-953. 